\title{
Modeling of Hydrological Extremes Under Climate Change Scenarios in The Upper Blue Nile River Basin, Ethiopia
}

\author{
Hadush K Meresa ${ }^{1 *}$ and Mulusew T Gatachew ${ }^{2}$ \\ ${ }^{1}$ Arbaminch University (AMU), Arbaminch, Ethiopia
}

${ }^{2}$ Addis Ababa University (AAU), Addis Ababa, Ethiopia

\begin{abstract}
The impact of climate change on modeling of hydrological extremes is needed to asses at regional and local scales since these vicissitudes are not uniform over the globe. This work stresses on climate change impact on the hydrological extremes (MMAX, CMAX, NNHF, Q10, MMIX, CMIX, MIN7, and Q90) and precipitation extremes (MLWD, MLDD, ADMT, ADMP) during the far future (2071-2100) period over the selected sites across the upper Blue Nile River basin (UBNRB), Ethiopia. The change in extreme indices were calculated based on daily precipitation and temperature data derived from the most recent CMIP5 climate projection scenarios compared to the reference period (1971-2000). The raw outputs from the climate models were corrected in order to reduce biases using distribution based quantile mapping technique. The validation and calibration demonstrates that the seasonal maximum cycle of precipitation and temperature in the reference period is reproduced reasonably in the bias-corrected climate results. The projections of climate change impacts on the hydrological extremes were evaluated using three generalize lump conceptual hydrological models: GR4J; HBV; HMETS and two objective functions: NSE and LogNSE. These hydrological models are calibrated in the period of 1971-2000 and validated in 2001-2010 period. The optimized hydrological parameters are adopted for the future hydrological simulations (2071-2100). The results indicate that the wet/dry spell will significantly decrease/increase due to climate change in some sites of the region (sites 2 and 6 ), while in sites 1 and 5 , there is increase/decrease in wet/dry spell but not significant, respectively. Far future maximum river flows in the study area will be less extreme and more variable in terms of magnitude, and more irregular in terms of seasonal occurrence, than they are at present. Low flows may become less extreme and variable in terms of magnitude, and more irregular in terms of seasonal occurrence. Most areas of northern, western, and northeastern part of the river basin will likely become wetter in the wet season and drier in dry season. Whereas, indices that related to low flows are projected to increase most prominently for lowland sites, due to the combined effects of projected decreases in summer precipitation, and projected increases in evapotranspiration that reduce residual soil moisture in late summer. Whereas the indices related to the high flows are projected slight increase in the central and upper part of the basin. According to the evaluated scenarios, climate change may have favorable impacts on the distribution of hydrological extremes in the study area.
\end{abstract}

Keywords: Blue Nile; Climate change; Ethiopia; Hydrological extremes; Modeling

\section{Introduction}

Extreme hydrology characteristics and available water resources, both in terms of quantity and quality, are significantly influenced by environmental changes, such as climate, land use, river engineering, construction of reservoirs and mining activities. Among the influences, climate change and land use change are two essential factors controlling the hydrological behavior of catchment such as river discharge [1] and water quality [2], hydrological extremes [3]. Particularly, climate change has huge influence on hydro-meteorological extremes of sub-Saharan countries [4,5]. Zhang et al., [6] compared the potential impacts in the near future streamflow using projected land use patterns and hypothetical climate scenarios. The result proves that land use changes in the near future period induce slight (non-significant) reductions in groundwater discharge and surface runoff whereas climate changes produce pronounced increases the streamflow. This shows the joint hydrological impacts are similar to those solely induced by climate changes. This is because of the global climate is changing and it will continue changing in future due to the atmosphere greenhouse gases, aerosols and human modifications of the land surface, a significant climate change is expected in the future [7]. According to the Intergovernmental Panel on Climate Change [7], the atmospheric concentration of $\mathrm{CO}_{2}$ has increased from $345 \mathrm{ppm}$ in 1750 to $405 \mathrm{ppm}$ in 2011, and is expected to reach $463-640 \mathrm{ppm}$ by 2050 and $800-1313 \mathrm{ppm}$ by 2100 . IPCC further indicates that the global average air temperature has increased over the $21^{\text {th }}$ century by about $0.9^{\circ} \mathrm{C} \pm$ $0.6^{\circ} \mathrm{C}$, and this increase is the largest of any century during the past 1000 years. Depending on the different emission scenarios, the IPCC projects a further increase of global air temperature in the range of $1.1^{\circ} \mathrm{C}$ to $4.8^{\circ} \mathrm{C}$. Intimately linked to changes in atmospheric temperature and radiation balance, a number of components of the hydrological cycle can be affected, such as changing precipitation patterns, intensity and extremes, increasing atmospheric water vapour, increasing evaporation and changes in soil moisture and runoff [8-10]. As a consequence, there is growing evidence worldwide of changing characteristics of stream flows and extremes $[11,12]$. Therefore, it requires to identify and quantify the change in extremes of precipitation, temperature and streamflow indices.

Many researchers in the world have been carried out to explore, understand and characterize the hydro-meteorological extremes $[2,3,11,13,14]$. These days, hydrological and meteorological extremes are highly and detailed reported in Europe and America context. However, of which many of the studies were point out that an increase in temperature will intensify the hydrological cycle and intense precipitation will increase, and Meresa et al., [11] concluded that this is a

*Corresponding author: Hadush $\mathrm{K}$ Meresa, Arbaminch University (AMU) Arbaminch, Ethiopia, Tel: +251-913332820; E-mail: kidane.hadush@gmail.com

Received September 01, 2016; Accepted October 03, 2016; Published October 05, 2016

Citation: Meresa HK, Gatachew MT (2016) Modeling of Hydrological Extremes Under Climate Change Scenarios in The Upper Blue Nile River Basin, Ethiopia. J Civil Environ Eng 6: 252. doi: 10.4172/2165-784X.1000252

Copyright: (c) 2016 Meresa HK, et al. This is an open-access article distributed under the terms of the Creative Commons Attribution License, which permits unrestricted use, distribution, and reproduction in any medium, provided the original author and source are credited. 


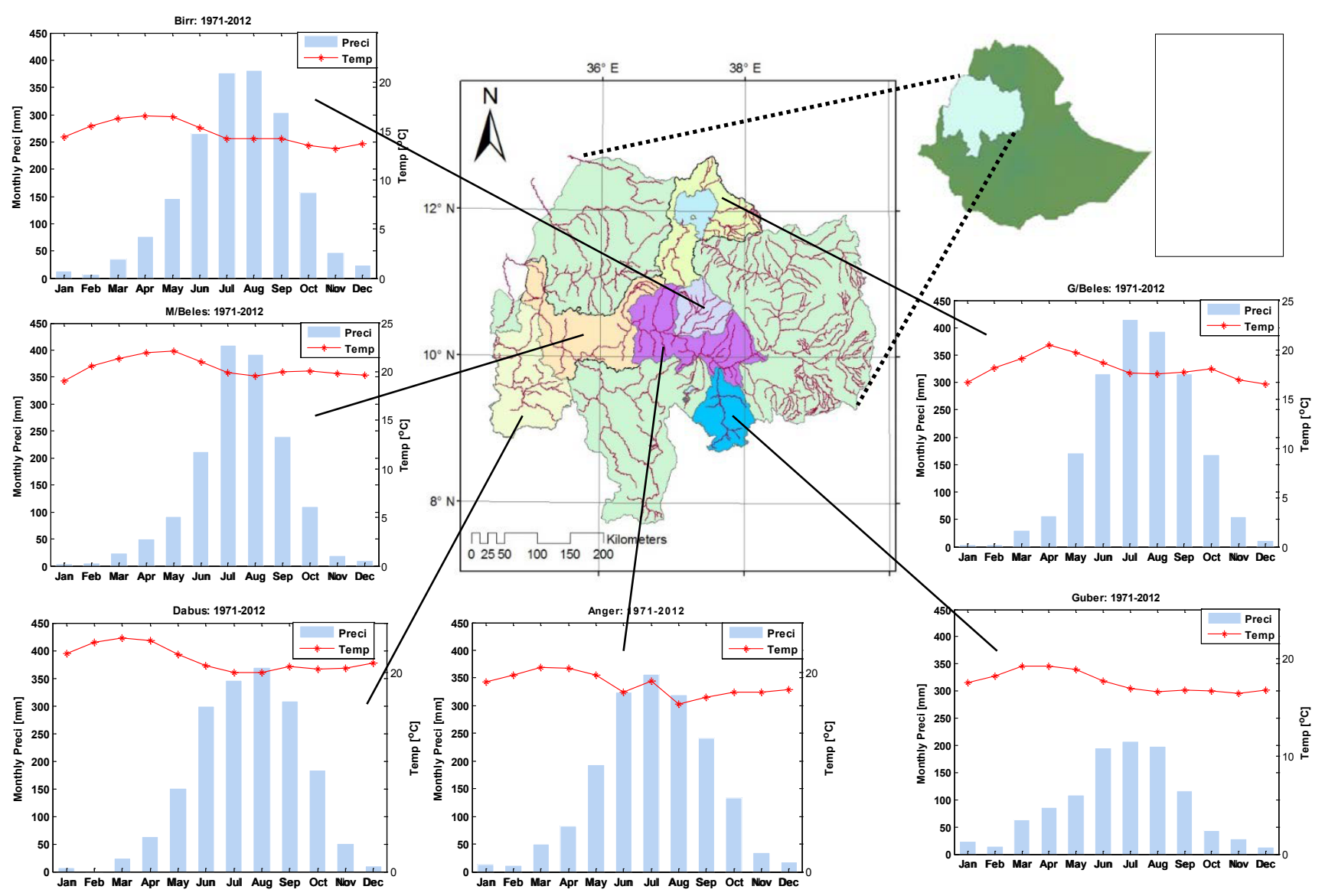

Figure 1: Location of selected stations and their seasonal precipitation and temperature characteristics.

precondition favorable for the development of hydro-climatic extremes and increase of hydro-meteorological drought. Indeed, Hattermann et al., [15] point out the intense precipitation has increased worldwide. Taye et al., [3] also mention that the increasing temperature projections indicate that potential evapotranspiration may simultaneously increase and leads to reduction in streamflow. Therefore, there is a growing need for information on climate change impacts on hydrological extremes [11,15-17] and related damages. Hoang et al., [18] come with a conclusion an increasing precipitation leads to make intensified the extremes globally. According IPCC, [19] report, more serious in the sub-Sahara, South Africa, and eastern Asia. As well as the indirect consequence will increase: risks to human safety, extreme hydrological events cause economic losses, and these costs are rising exponentially [20], threatening sustainable development. Management and planning in water resource management refers to the time scale of decades, hence measures implemented now should already take into account possible future climate change impacts on hydrology and water resource [15]. There is a need then to improve the scientific understanding of changes and patterns in extreme hydrological events in the context of global climate change and regional climate changes to inform planning and management for water resource, disaster protection and alleviation in local/catchment scale. Also, the climate model simulation outputs are not always in a good accordance with observations time series of precipitation and temperature $[11,21,22]$. This means there may be some biases associated with the models. Sometimes, heavy rainfall and number of heavy rain days (as well as their magnitude) are not well reproduced by RCMs [17]. Bias correction is therefore necessary in order to improve the input data for climate change impact assessments.
The bias-corrected data is useful in the studies of impacts of climate change to extreme events and can be used as an input to other climate impact studies such as water resource, agriculture and environments. We investigate the impacts of climate change in hydrological extremes on the selected sites from the main Blue Nile River basin, Ethiopia. In particular our aims are: (i) to compare and evaluate three hydrological models (HMTS, GR4J and HBV) with two objective function (one for low flow and the other for high flow) for climate change impact study, ii) evaluation of climate models for impact analysis and iii) to quantify the changes and patterns in extreme indices derived from projected precipitation, temperature and streamflow. The next section briefly description of the data input, study area and the hydro-climatic characteristics of the selected catchments (section 2). In section 3 briefly describes the overall modelling strategy and the models used and information about climate models and their bias correction method, also the hydrological indicators are explained well in this section. The result and discussions of climate model validating, hydrological modeling calibration and validation, and impact of climate change in extreme precipitation, temperature and streamflow are presented in Section 4. Finally, we summarize the results and conclude our research findings in Section 5.

\section{Study Area Description and Data Input}

\section{Hydrology and size of the basin}

The UBNRB originates in the highlands of Ethiopia. About $75 \%$ of the Nile's waters originate in Ethiopia and Eretria, while the majority of the river's water is used in the Sudan and Egypt. The Blue Nile basin 


\begin{tabular}{|c|c|c|c|c|c|}
\hline Code & River name & Guaged site & Latitude & Longitude & Area [km ${ }^{2}$ ] \\
\hline S1 & Main Beles & @ BRIDGE & 11.25 & 36.45 \\
\hline S2 & Dabus & Nr. Asosa & 9.87 & 34.9 \\
\hline S3 & Guder & @ Guber & 8.95 & 37.75 \\
\hline S4 & Anger & @ Angar G & 9.5 & 36.58 \\
\hline S5 & Gilgel Beles & Nr. Mandu & 11.17 & 36.37 \\
\hline S6 & Birr & Nr. Jiga & 10.65 & 37.38 \\
\hline
\end{tabular}

Table 1: List of selected catchments in this study.

\begin{tabular}{|c|c|c|c|c|}
\hline GCM name & Acronyms & Institution & Resolution \\
\hline CanESM2 & CGCM4 & Canadian Centre for Climate modeling and analysis & $1.75 \times 1.75$ \\
\hline CCSM4 & CCSM & NCAR-National Center for atmospheric research center & $1.25 \times 0.94$ \\
\hline CNRM-CM5 & CM5 & national de researches meteorologiques & $1.9 \times 1.9$ \\
\hline CSIRO- Mk3.6.0 & CSIRO & Commonwealth Scientific-climate change center of excellent & $1.87 \times 1.87$ \\
\hline HadGEM2-ES & HadGEM & Arance & Australia \\
\hline MIROC5 & MIR & Japan Agency for Marine-Earth Science and Technology & $1.87 \times 1.24$ \\
\hline MPI-ESM-LR & MPI & Japan & $1.95 \times 1.95$ \\
\hline
\end{tabular}

Table 2: List of GCMs/RCMs models used in this study.

lies in the west of Ethiopia, between $7^{\circ} 45^{\prime}$ and $12^{\circ} 45^{\prime} \mathrm{N}$, and $34^{\circ} 05^{\prime}$ and $39^{\circ} 45^{\prime} \mathrm{E}$ and it covers an area of $199,812 \mathrm{Km}^{2}$, with total perimeter of $2862 \mathrm{~km}$ (Figure 1). As indicated in the Master Plan of BNRBMain Report, [23], UBNRB accounts for almost $17.1 \%$ of Ethiopia's land area, about $50 \%$ of its total average annual runoff and $25 \%$ of its population. The Abbay Rivers has an average annual runoff of about 50 billion billion cubic meter (BCM). The rivers of the UBNRB contribute on the average about $62 \%$ of the average Nile total at Aswan Dam. It also indicates there are sixteen main sub basins in the River Basin. However, in this study we select six of them as indicated in the Figure 1 and Table 1 with their corresponding aerial coverage.

\section{Climate}

Blue Nile has diverse climates, ranging from semi-arid desert in the lowlands to humid and warm (temperate) in the southwest. The climate of Abbay basin is dominated by an altitude ranging from 590 meters to more than 4000 meters. The influence of this factor determines the rich variety of local climates ranging from hot to desert-like climate along the Sudan boarder with mean temperature of the coldest month above $18^{\circ} \mathrm{C}$, to temperate on the high plateau, and cold on the mountain peaks, with mean temperature of the warmest month below $10^{\circ} \mathrm{C}$. But the annual rainfall varies between about 800

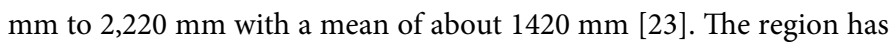
three major climatic seasons: The dry season (Bega) from October to January; the short rainy season (Belg) from February to May; and the long rainy season (Kiremt) from June to September. Mostly the climate in the study area are controlling by three major weather systems, which are the ITCZ (Intertropical Convergence Zone) that drives the monsoon rainfall during the wet season (June-September), the Saharan anticyclone that generates the cool and dry northeasterly winds in the dry season (Octomber-February); and the Arabian highlands that produce thermal lows in the hot season (March-May) [24].

\section{Observed hydro-meteorological data}

The daily precipitation, minimum and maximum temperature records for the study area are collected from National Meteorological Agency (NMA) for about 30 stations which cover entire selected river basins for the period 1971 to 2012 (Figure 1). Hydrological data for the year 1971 to 2010 of six major rivers were collected from Ministry of Water Resources (MoWR) hydrology department, Ethiopia (Table 1). We calibrated and validated six sites/catchments, which are selected from different hydro-climatic conditions. The study area has a season of highly variable rainfall from February to June, a wet season from
July to September, and dry season from October to January. Whereas, around $50 \%$ of the annual rainfall is received during the three months' wet season, rainfall distribution is highly varying and long dry periods are common. The monthly average rainfall pattern of rainfall as per the rainfall data records of six areal precipitation and temperature from the meteorological stations available in and around each catchment are as shown in Figure 1.

It is important to assess and evaluate how climate has varied and changed in the past. The monthly mean observed precipitation and mean daily air temperature data can be plot to show the observed climate and seasonality by month, for specific years, and for precipitation and temperature. Figure 1. Shows mean observed monthly temperature and precipitation for the selected catchments of the UBNRB during the time period 1971-2012. The input rainfall and PET data were calculated as weighted average time series from point measurements using the Thiessen polygon method. Hamon method $[25,26]$ was used for estimating PET. Due to lack of data for all the required climatic inputs, the Hamon method of estimating PET with limited data was applied in the research. The method estimates potential evapotranspiration based on mean daily air temperature and central catchment elevation. It is important to mention that for the climate model evaluation, only one station in each catchment was used for calculating the biases.

\section{Future precipitation and temperature: GCMs/RCMs data}

The Coordinated Regional Climate Downscaling Experiment (CORDEX; Giorgi and Gutowski, [27]) was designed to produce an improved regional climate change projection as part of the IPCC Fifth Assessment Report (AR5) and to standardize the generation and evaluation of regional climate projections across multiple modelling centers. As part of the CORDEX project, several regions were established with explicitly defined domains and model resolutions. This study relies on the CORDEX dataset, which contains regionally downscaled CMIP5 climate projections [28] across the world. Therefore, we used mean daily precipitation and daily average air temperature from three greenhouse gas concertation paths adopted by the IPPC for its fifth assessment report (AR5). We therefore downscaled the GCM projections ourselves. Given the relatively large number of GCMs under CMIP5, we first did a model selection by reviewing literature on GCM performance. We selected those GCMs that better reproduce historic temperature and precipitation conditions, implying their suitability to be used in the region. We selected seven General Circulation models/ regional climate Models (GCMs/RCMs) for this study (Table 2). For 


\begin{tabular}{|c|c|c|c|}
\hline Model name & HBV & HMETS & GR4J \\
\hline Model structure & Conceptual & Conceptual & Conceptual \\
\hline Spatial discretization & Semi-distributed & Lumped & Lumped \\
\hline Time step & Daily/hourly & Daily & Daily \\
\hline Input data & $\mathrm{T}_{\text {mean }}, \mathrm{P}$ & $\mathrm{T}_{\min }, \mathrm{T}_{\max }, \mathrm{P}$ & $\mathrm{T}_{\text {mean }}, \mathrm{P}$ \\
\hline Possible for modification & yes & yes & yes \\
\hline Physiographic info & Required & No-required & No-required \\
\hline Automatic parameter calibration & yes & yes & yes \\
\hline
\end{tabular}

Table 3: Main properties of the hydrological models. Precipitation $(P)$, mean temperature $\left(T_{\text {mean }}\right)$, maximum temperature $\left(T_{\text {max }}\right)$, minimum temperature $\left(T_{\text {min }}\right)$.

each GCMs/RCMs, we extracted climate data for three different RCP s, namely RCP 2.6, RCP 4.5 and RCP 8.5. The RCP 4.5 is a medium to low scenario assuming a stabilization of radiative forcing to 4.5 $\mathrm{W} / \mathrm{m}^{2}$ by 2100 [29]. The RCP 2.6 is a lower radiative forcing level for lowest emission scenarios [30]. The RCP 8.5 is a high radiative-forcing scenario assuming a rising radiative forcing leading to $8.5 \mathrm{~W} / \mathrm{m}^{2}$ by 2100 [31]. By selecting from lower-range to mid-range and a highend scenario, we expect to capture a reasonable range in climatic and hydrological extreme projections for the UBNRB, Ethiopia.

\section{Materials and Methods}

\section{Climate projection: Climate bias correction}

It is known that GCMs/RCMs have biases and correction of these biases is necessary prior to use of the outputs [32]. Bias correction is the process of adjusting GCMs/RCMs output; mainly temperature and precipitation depending on discrepancies between observed and modeled results over the period of observation. In this study we used distribution mapping method developed by Piani et al., [33] to correct the bias of climate models output. The idea of distribution mapping is to correct the distribution function of RCM-simulated climate values to agree with the observed distribution function. This can be done by creating a transfer function to shift the occurrence distributions of precipitation and temperature [33,34]. The Gamma distribution with shape parameter $\alpha$ and scale parameter $\beta$ (Eq. (1)) is often assumed to be suitable for distributions of precipitation events:

$$
\mathrm{f}_{\mathrm{y}}(\mathrm{x} / \alpha, \beta)=\mathrm{x}^{\alpha-1} \cdot \frac{1}{\beta^{\alpha} \cdot \Gamma(\alpha)} \cdot \mathrm{e}^{\frac{-x}{\beta}} ; x \geq 0 ; \alpha, \beta>0
$$

This distribution has been proven to be effective for the analysis of precipitation data in previous studies. The shape parameter a controls the profile of the distribution: (1) $a<1$ indicates an exponentially shaped Gamma distribution which is asymptotic at both axes, (2) $a=1$ is a special case and characterizes an exponential distribution and (3) $\alpha>1$ shapes a skewed unimodal distribution curve. The scale parameter $\beta$ determines the dispersion of the Gamma distribution. A smaller $\beta$ leads to a more compressed distribution and, therefore, to lower probabilities of extreme events. A larger $\beta$, on the other hand, causes a stretched distribution, which implies higher probabilities of extreme events.

For temperature time series, the Gaussian distribution with location parameter $\mu$ and scale parameter $\sigma$ (Eq. (2)) is usually assumed to fit best:

$$
\mathrm{f}_{N}\left(\mathrm{x} /, \sigma^{2}\right)=\mathrm{x}^{\alpha-1} \cdot \frac{1}{\sigma \cdot \sqrt{2 \pi}} \cdot \mathrm{e}^{\frac{-(x-\mu)^{2}}{\beta}} ; x \in R
$$

The scale parameter $r$ determines the standard deviation, i.e., how much the range of the Gaussian distribution is stretched or compressed. A smaller value for $\sigma$ results in a more compressed distribution with lower probabilities of extreme values. Contrary, a larger value for $\sigma$ indicates a stretched shape with higher probabilities of extreme values. The location parameter $\mu$ directly controls the mean and, therefore, the location of the distribution.

\section{Description of hydrological models}

The choice of a hydrological model for hydrologic applications in a given basin is a challenge. The available information is of great importance. In this study, based on the information we have about the river basin, oriented us towards to use lumped conceptual hydrologic models. Three hydrological models were used, namely two lumped conceptual models (GR4J and HMETS) and one semi-distributed conceptual model (HBV). The rationale for using three models displaying a range of model structures was that it would provide a clearer understanding of the importance of this particular factor in modeling extremes. Table 3 outlines the general properties of the hydrological models used in this study.

HBV (Hydrologiska Byrans Vattenbalansavdelning) model: The HBV model is a conceptual rainfall-runoff model of catchment hydrology which simulates discharge using temperature, rainfall and potential evaporation [35]. The model was developed for runoff simulation and hydrological forecasting [36]. The advantage of HBV is that it covers the most important runoff generating processes by quite simple and robust structures where topographic and climate parameters serve as driving forces. Besides, HBV does not require extensive data sets. The HBV model [35] has been applied in numerous studies, e.g., to compute hydrological forecasts, for the computation of design floods or for climate change studies. HBV has been applied in more than 40 countries all over the world. It has been applied to countries with such different climatic conditions as for example Europe (Sweden), South America (Colombia), Asia (India) and Africa (Zimbabwe) [11,17].

The model consists of a precipitation routine representing rainfall and snow, a soil moisture routine determining actual evapotranspiration, overland flow and subsurface flow, a fast flow routine representing storm flow, a slow flow routine representing subsurface flow, a transformation routine for flow delay and attenuation and a routing routine for river flow.

GR4J (modèle du Génie Rural à 4 paramètres Journalier) model: The GR4J conceptual hydrological model has a parsimonious structure with four calibration parameters and has been frequently applied over hundreds of catchments worldwide [11,37-39], with a broad range of hydro-climatic conditions from arid to semiarid and tropical to temperate catchments [40]. The GR4J model requires only daily time series of temperature and precipitation and potential as inputs (Table 3). The four parameters in GR4J represent the maximum capacity of the production store (X1), the groundwater exchange coefficient (X2), the 1 day ahead capacity of the routing store (X3), and the time base of the unit hydrograph (X4). All four parameters are used to calibrate the model based on Tian et al., [41] and Thyer et al., [42]. The upper and lower limits are selected based on previous works $[40,41,43]$. Production Store(X1) is storage in the surface of soil which can store rainfall. There are evapotranspiration and percolation in this storage. Groundwater exchange coefficient (X2) is a function of groundwater exchange which influence routing store. Routing storage(X3) is amount of water which that can be storage in soil porous. Time Peak (X4) is the time when the 
ordinate peak of flood hydrograph is created on GR4J modeling. The ordinate of this hydrograph is created from runoff, where $90 \%$ of flow is slow flow that infiltrates into the ground and $10 \%$ of flow is fast flow that flows on the soil surface.

HMETS (Hydrological Model of Ecole de Technologie Supérieure) model: HMETS is a lumped conceptual rainfall-runoff model developed at the Ecole de Technologie Supe'rieure [44], which is using two connected reservoirs for the vadose and saturated zones. It has been used in multi-model averaging projects [45] and in climate change impact studies [9]. The model simulates the basic hydrological processes: evapotranspiration, infiltration, snow accumulation and melting as well as flow routing to the catchment outlet. It is a MATLAB-based freeware, and has up to 20 free parameters: 10 parameters for snowmelt, one for evapotranspiration, four for infiltration, and five for upper and lower soil reservoirs. The HMETS model calibration is done automatically using the SCE-UA [46], and it accounts for snow accumulation, snowmelt, soil freezing/thawing, and evapotranspiration. The basin-averaged minimum required daily input data for HMETS are Tmax, Tmin, liquid and solid precipitation, or total precipitation. A natural inflow or discharge time series is needed for proper calibration/validation.

\section{Hydrological model evaluation}

The parameters of the hydrological models are optimized with SCE-UA method, is a global searching algorithm proposed by Duan et al., $[46,47]$ and it has been used in many hydrological models. The SCE-UA method combines the direction-searching of deterministic and the robustness of stochastic, non-numerical methods to obtain a global optimal estimation [48] To make the implementation more convenient, Duan suggested some default values for the parameters of the SCE-UA method $[46,47]$.

The objective functions used in this study include both normal (NSE) and logNSE measures as suggested by Nash and Sutcliffe [49] The efficiency NSE proposed by Nash and Sutcliffe (1970) is defined as one minus the sum of the absolute squared differences between the predicted and observed values normalized by the variance of the observed values during the period under investigation. It is calculated as:

$$
N S E=1-\frac{\sum_{i=1}^{n}\left(\mathrm{O}_{\mathrm{i}}-\mathrm{P}_{\mathrm{i}}\right)^{2}}{\sum\left(\mathrm{O}_{\mathrm{i}}-\overline{\mathrm{O}} \mathrm{o}\right)^{2}}
$$

Where: NSE is the Nash-Sutcliffe coefficient. For an acceptable model performance, NSE should be close to 1 . The calibration period is from 1971 to 2000 and the validation period is from 2001 to 2010 . The model is calibrated for the original and each of the adapted discharge series using SCEM-UA [50,51].

\section{Hydro-meteorological extreme indicators/indices}

There are a number of hydro-meteorological measures exists to describe the statistical properties of extreme hydrological and meteorological events. In terms of high flow, low flow, dry spell, wet well, and hot temperature, the following measures are considered in this study:

- Dry weather flow, MIN7, defined as the average annual 7-day minimum river flow.

- MLDD index is the number of consecutive dry days (i.e. maximum length of dry spell; $R R<1 \mathrm{~mm}$ ), where $\mathrm{RR}$ is daily precipitation.

- MLWD index is the number of consecutive wet days (Maximum length of wet spell, maximum number of consecutive days with $R R$ >= $1 \mathrm{~mm}$ ), where RR is daily precipitation.

- ADMT index is maximum value of daily maximum temperature.

- Average annual maximum/minimum daily river flow, MAX/ MIN, defined as the average value of a time series consisting of annual maximum/minimum daily river flows.

- Coefficient of variation of annual maximum/minimum daily flows, CMAX/CMIN, a dimensionless measure of the variability of annual maximum/minimum river flow magnitudes.

- The number of high flows, NHF, i.e. flows greater than $\mathrm{Q}=\alpha+3^{\star}$ $\sigma$, where $\alpha$ and $\sigma$ are the average and standard deviation of daily river flow series.

- The $90^{\text {th }} / 10^{\text {th }}$ percentile flow, $\mathrm{Q}_{90} / \mathrm{Q}_{10}$, defined as the river flow which is equaled or exceeded for $90 \% / 10 \%$ of the period of record, which is determined from a flow duration curve.

\section{Results and Discussions}

To investigate climate change impact on the hydrological extremes over the period of 2071 to 2100 , we use calibrated lump conceptual hydrological model (HBV) for the selected river basins, was simulated. The input of hydrological model, projected precipitation, temperature and PET were derived from different GCMs/RCMs for RCP 2.6, RCP 4.5 and RCP 8.5 emission scenarios after applying a distribution based quantile mapping technique. The results of climate change impact on the hydrological extremes have been presented in following sections.

\section{Evaluation of the climate models: Bias correction}

The bias is defined as long term average difference between climate model output and observation. This shows how well the best available climate models capture the seasonal cycle of precipitation and temperature for the selected sites/catchments. The evaluation of climate model biases of precipitation and temperature are shown in Figure 2. Figure 2 shows the annual cycle of monthly biases of precipitation (left column) and temperature (right column). In this case, the error variability is indicated by box-and-whisker plots. The bias correction was evaluated by split the sample into two, one for calibration in the period 1971 to 1991 (blue) and the second part for validation in the period 1992 to 2012(green), together with the raw RCM bias of each period (dark blue (1971-1991) and dark green (19922012)), respectively. This way of bias evaluation can help to understand the non-stationarity characteristics of precipitation in the area. In the case of temperature, calibration in the period 1971 to 1991 (red) and validation in the period 1992 to 2012 (orange), together with the raw RCM bias of each period (dark red (1971-1991) and dark orange (1992-2012)), respectively. The monthly timescale (Figure 2), the result evaluated in both calibration and validation period, corrected models have smaller biases and smaller bias ranges than the raw models. The bias correction successfully reduces biases during the calibration (1971-1991) and validation (1992-2012) period. This implies, the bias correction technique performs reasonably well in preserving the variability and magnitude of mean monthly precipitation in most months though there is a relatively insignificant model error. In all the sites and climate models, the larger bias was observed in the main rain season (June, July, August and September) of the region. For instance at Figures 2a, 2b, and 2c, the RCP 4.5 scenario shows overestimation ranging from $1 \mathrm{~mm}$ to $9 \mathrm{~mm}$ at months for June to September and underestimation ranging from $1 \mathrm{~mm} /$ day to $7 \mathrm{~mm}$ /day for the months of April to May. In general, the raw RCM simulations of precipitation have modest biases (within -5 to +10 in RCP 4.5 and 

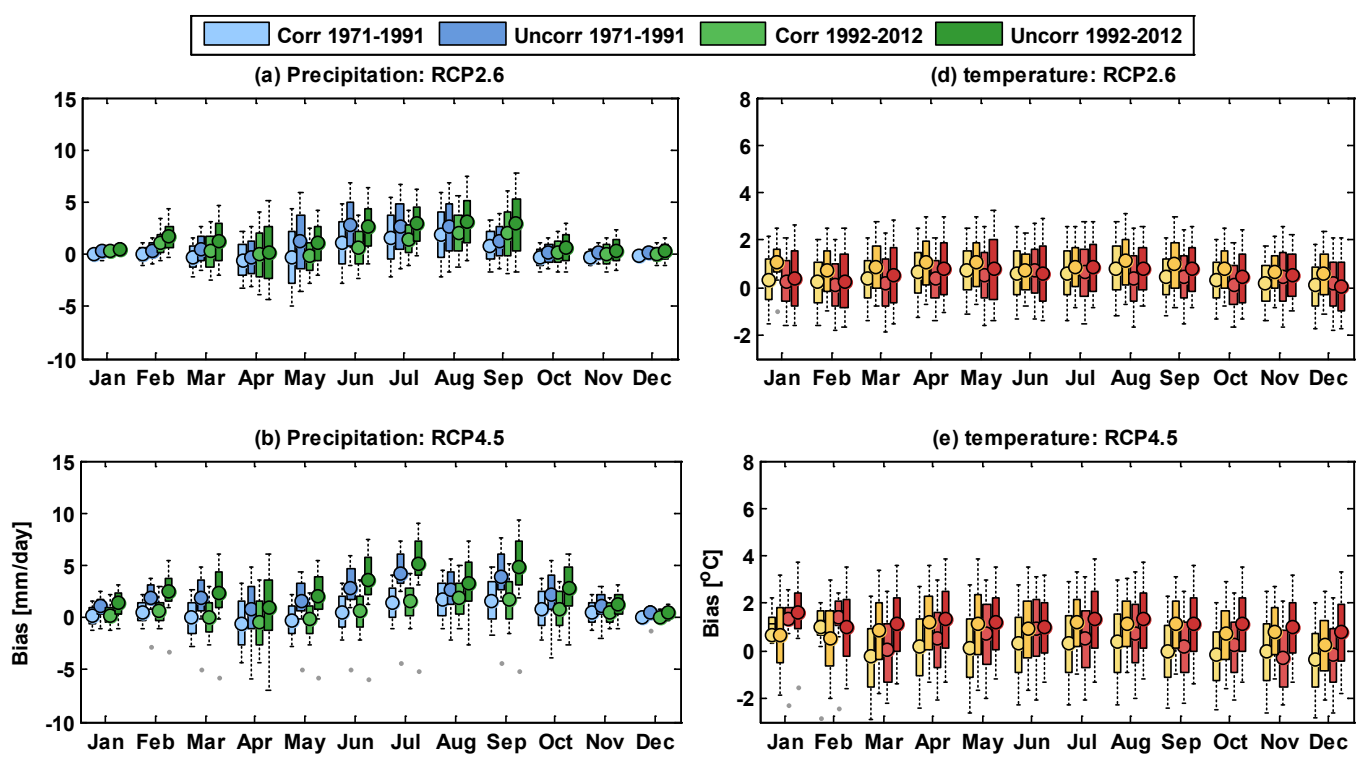

(c) Precipitation: RCP8.5
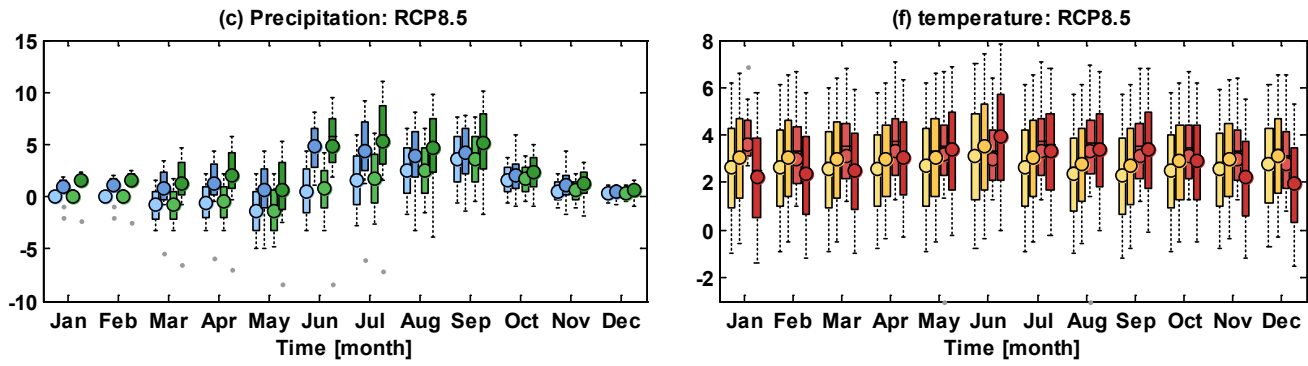

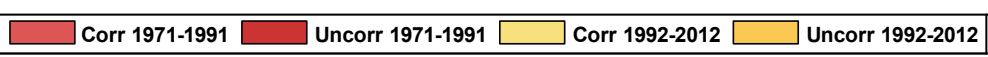

Figure 2: Monthly bias of precipitation (left column) and temperature (right column) as box-whisker plots for the uncorrected RCM split in two periods (dark green and dark red), the corrected RCM with split to two periods for evaluation (light blue and light orange). Box and whiskers indicate the variability of errors at site1 (S1). Boxes indicate the first (PT25) and the third (PT75) quantile, the whiskers extend to PT5 and PT95, and the black circle indicates the median of the climate models for each climate scenarios.

$-10 \%$ to $15 \%$ in RCP 8.5 ) in the mountainous sites/catchments than lowland sites, which show relatively higher bias in the lowland sites than mountainous sites. However, the biases are behaving different for different emission scenarios (RCP 2.6, RCP 4.5 and RCP 8.5), which indicates that the biases in precipitation are smaller in the RCP 2.6 compare the other scenarios and in the RCP 8.5 the biases are relatively larger. This is because of lowest radiative forcing and substantial decline of greenhouse gases concentration in RCP 2.6 leads to have small bias and variability, whereas in scenario RCP 4.5 is characterized by very small increases of greenhouse concentration. RCP 8.5 is characterized by more than double increment in greenhouse gases concentration, which implies with higher bias and variability in precipitation.

Figures $2 \mathrm{~d}, 2 \mathrm{e}$ and $2 \mathrm{f}$ show the annual cycle of monthly biases in air temperature. In this case, the biases and their variability are generally strongly reduced. In some months, however, considerable errors remain after the correction (e.g., months belonging to Belg season), which is caused by different model error characteristics in the calibration and validation period (i.e. by non-stationarity). It can be concluded that the bias correction for temperature leads to satisfactory results. Corrections are largest during the Bega months and smallest during Kiremt. This is mainly caused by the difference in mean temperature as shown later in Figures 2d, 2e and 2f. This result indicates that using the RCM output without doing bias correction may lead to enormous uncertainty of hydrological analysis.
Table 4 presents a bias between corrected and uncorrected precipitation and temperature over the ensemble of climate models. The most pronounced biases occur for simulations of precipitation, in particular in the north and central, a region with steep topographic and precipitation gradients Table 4 . The climate model tends to underestimate precipitation on the central and north mountains by $15 \%$ or more, while it tends to greatly overestimate precipitation $(>15 \%)$ in the low-precipitation of lower part of the River basin. The temperature behaves opposite to precipitation, which is over estimated in the lowland part of the basin and understated over the mountainous region. so, as conclusion the temperature and precipitation biases in the uncorrected simulations are high in the north-east and north largely because of orographic rainfall effects (in this case, a rain shadow caused by a steep topographic gradient from the mountainous north to the lowlands in the north east part of the upper Blue Nile River basin, Ethiopia.

\section{Projected precipitation and temperature indices}

Figure 3 illustrates the temporal variability and distribution of selected indices derived from projected precipitation and temperature variables over the selected six sites from the upper Blue Nile River Basin. In this study indices namely, maximum length of dry spell (MLDD), maximum length of wet day (MLWD), annual daily maximum precipitation (ADMP) and annual daily maximum temperature 
Citation: Meresa HK, Gatachew MT (2016) Modeling of Hydrological Extremes Under Climate Change Scenarios in The Upper Blue Nile River Basin, Ethiopia. J Civil Environ Eng 6: 252. doi: 10.4172/2165-784X.1000252

Page 7 of 15

\begin{tabular}{|c|c|c|c|c|c|c|}
\hline \multicolumn{2}{|c|}{ Variable } & West & East & North & South & Central \\
\hline \multirow{3}{*}{ Temperature } & rcp26 & -2.3 & 3.0 & 9.0 & -3.0 & 4.2 \\
\hline & rcp45 & -5.5 & 7.0 & 13.0 & -1.0 & 5.7 \\
\hline & rсp85 & -8.1 & 10.0 & 9.0 & -3.0 & 2.5 \\
\hline \multirow{3}{*}{ Precipitation } & rcp26 & 13.0 & -7.8 & -13.0 & 11.0 & -14.0 \\
\hline & rcp45 & 14.2 & -7.1 & -17.0 & 15.0 & -18.0 \\
\hline & rсp85 & 12.5 & -9.5 & -11.0 & 19.0 & -12.0 \\
\hline
\end{tabular}

Table 4: Over all bias in precipitation ( $\mathrm{mm} /$ day) and temperature $(\mathrm{OC})$ bias.
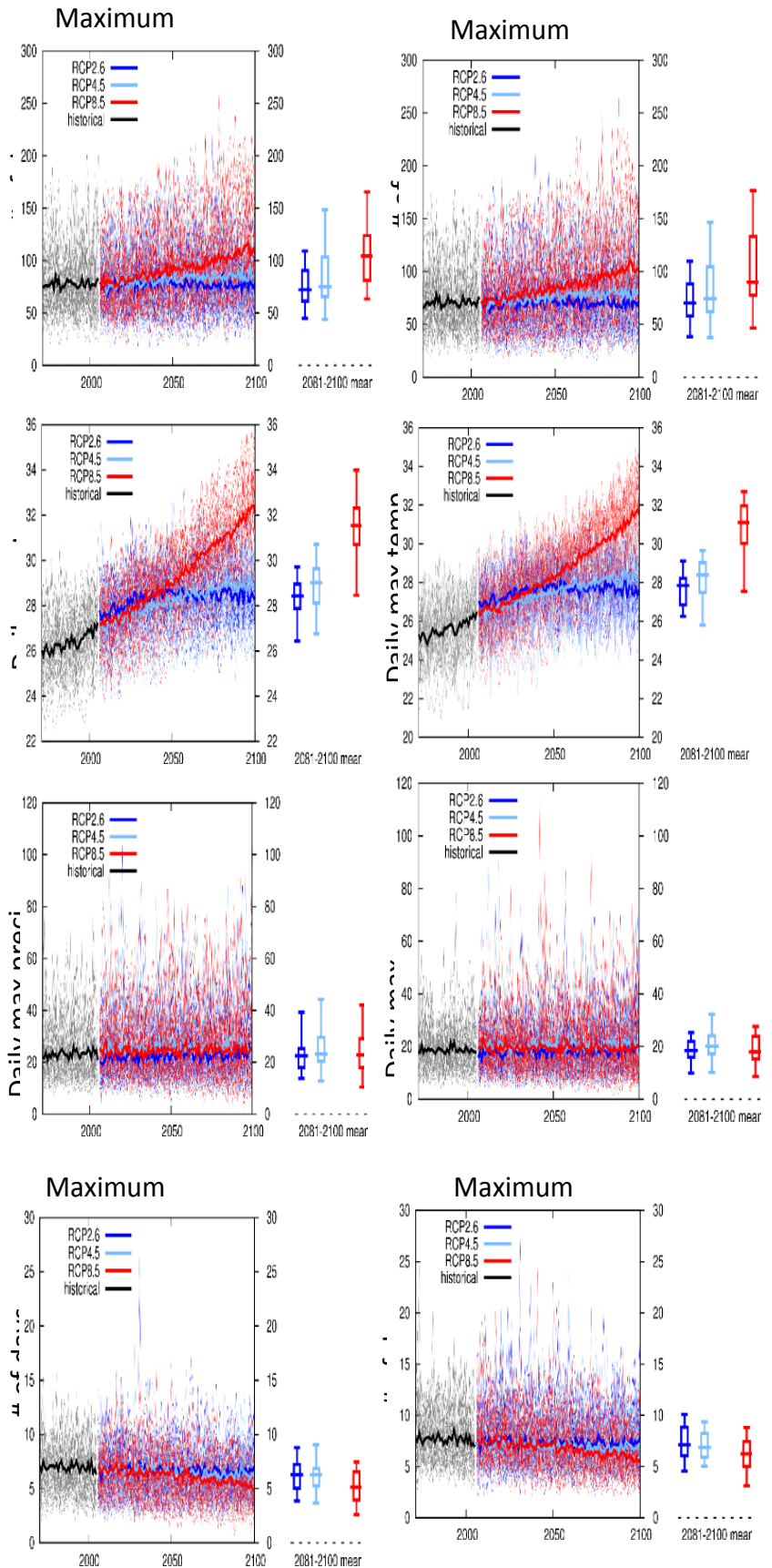

Figure 3: Relative maximum number of wet spell days (top panel), Relative maximum number of dry spell days (middle panel) and annual maximum temperature for full CMIP5 ensemble. On the left, for each scenario one line per model is shown plus the multi-model mean, on the right percentiles of the whole dataset: the box extends from $25 \%$ to $75 \%$, the whiskers from $5 \%$ to $95 \%$ and the horizontal line denotes the median $(50 \%)$. The right columns are for catchment-one and the second columns are for catchment-two.
(ADMT) are selected from projected climate time series. As a result, Figure 3 shows that the station (right column: site 1) is dominated by increasing ADMT and MLDD. While the ADMP shows either of increasing nor decreasing but the variability is increasing with time. Most stations are identified by increasing dry spell length (MLDD), nevertheless, only two sites located at the north and central part of the basin are characterized by significant increasing in MLDD. The MLDD and ADMT in the station have increased with time, as well as slight decrease in daily precipitation extremes. This could be attributed to a combined effect of global warming, anthropogenic influences, natural climate variability (such as NAO, ENSO,), etc. MLWD is slightly decrease with time and this index has highly diverse spatially (among the selected sites). Mean MLWD in site 1 (Figure 3: right column) is around 6 days and 8 days in site 2 (Figure 3: left column). Mean MLDD of precipitation increases from 80 days to 110 days in site 1 , while in site 2 its increases from 65 days to 100 days. The mean value of the indices in the far future (2071-2100) shows different by different climate scenarios and models. Among the scenarios RCP 8.5 shows larger increasing in MLDD and larger decreasing in MLWT, similar condition also happens for ADMT and ADMP in the far future. While RCP 4.5 produce reasonable change in mean indices in the far future. Such difference is appearing due to the difference in radiation force level. The higher radiation force produces drier future.

Inter-model spread is large particularly over the south and west part of the river basin, this leads to have higher bias in the ensemble mean estimation for projected impact analysis. Over the North and central parts inter-model agreement is found to be higher, with about $90 \%$ of models agreeing on projected indices.

The number of seasonal Kiremt, Belg and Bega wet days, dry days and maximum temperature at selected six sites in the upper Blue Nile river basin Region is depicted in Table 5 . The observed number of wet days in Kiremt season varied from 21 days at site 2 to 61 days at site 6 . On average, there were more MLWD in a year at site 5. Temporally, there was more variability in the MLWD at site 2 and conversely, less at site 6 than the other sites studied during 2071-2100. On the other hand, in Belg season MLDD varied from 41 days at site 3 to 80 days at site 5 during 2071-2100 (Table 5). There were, on average, more Belg season MLDD in a year at site 4 than the rest of the sites studied. The Belg season showed that there was moderate to high inter annual variability in the MLDD at all the studied sites. This indicates that the MLDD in the Belg season was less dependable in the study area. Moreover, the seasonal Belg MLDD varied from 41 days at site 3 to 80 days at site 5 . Moreover, the present study has shown that the number of rainy days was more variable during the Belg season than during the Kiremt season, and the number of dry days was less variable than the number of rainy days in both seasons. From hydrology, hydraulic structure, agricultural point of view, high inter annual variability in the number of rainy days shows less dependability of the rains for planning activities which may lead to crop failures, longer dam/reservoir filling time and challenging in hydrological operation. Particularly, the high variability of rainy days for the Belg season could be a great problem for farmers who lack instruments to quantify rainfall amount but rather depend on number of rainy days to plan cropping calendar. 


\begin{tabular}{|c|c|c|c|c|c|c|c|c|c|}
\hline & Bega & & & Belg & & & Kiremt & & \\
\hline & MLDD & ADMT & MLWD & MLDD & ADMT & MLWD & MLDD & ADMT & MLWD \\
\hline Site1 & 77 & 21.4 & 1.75 & 55 & 20 & 25 & 48.95 & 16 & 45 \\
\hline Site 2 & 102.2 & 27.82 & 0.84 & 73 & 26 & 12 & 64.97 & 20.8 & 21.6 \\
\hline Site 3 & 57.4 & 18.19 & 0.98 & 41 & 17 & 14 & 36.49 & 13.6 & 25.2 \\
\hline Site 4 & 70 & 20.33 & 1.82 & 50 & 19 & 26 & 44.5 & 15.2 & 46.8 \\
\hline Site 5 & 112 & 22.47 & 1.96 & 80 & 21 & 28 & 71.2 & 16.8 & 50.4 \\
\hline Site 6 & 89.6 & 19.26 & 2.38 & 64 & 18 & 34 & 56.96 & 14.4 & 61.2 \\
\hline
\end{tabular}

Table 5: Seasonal characteristics of the indices.
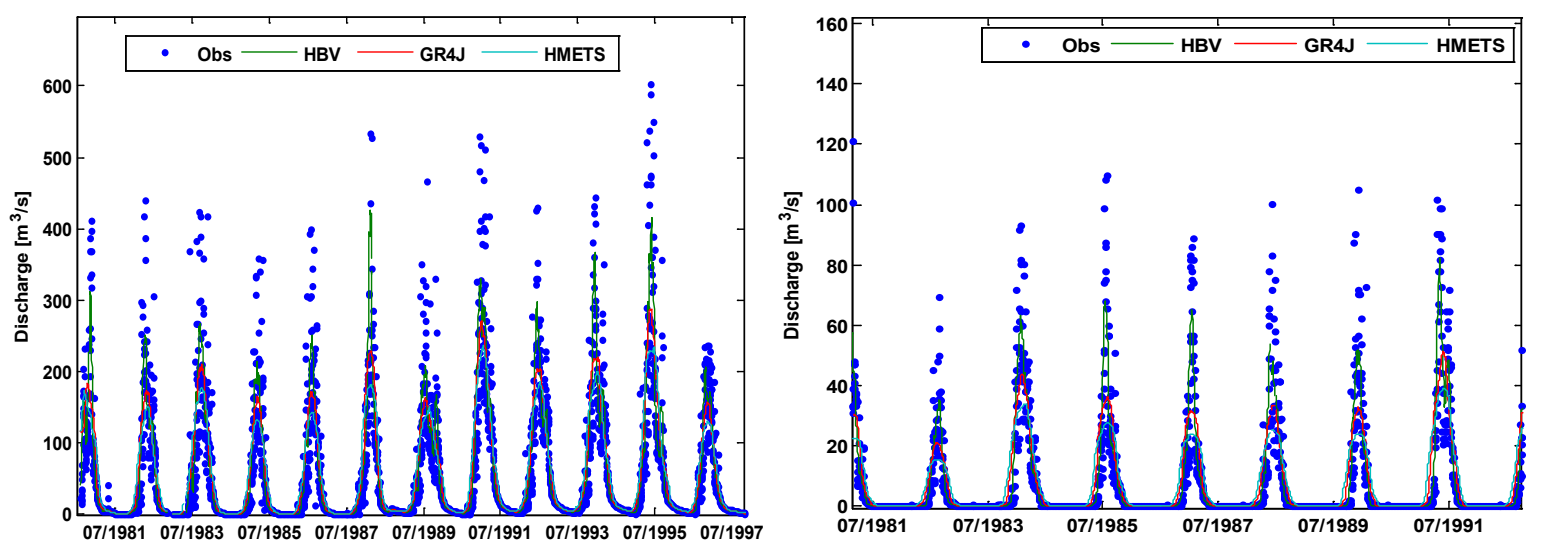

Figure 4: Observed and simulated discharge hydrograph from three hydrological models in the period of July/1981 to July/1997. Calibration result at site 1 (left) and site 5 (right).

\begin{tabular}{|c|c|c|c|c|c|c|c|c|c|c|c|c|}
\hline & HBV & & & & GR4J & & & & HMETS & & & \\
\hline Sites & NS & & LogNS & & NS & & LogNS & & NS & & LogNS & \\
\hline & Cal & Val & Cal & Val & Cal & Val & Cal & Val & Cal & Val & Cal & Val \\
\hline S1 & 0.83 & 0.72 & 0.68 & 0.73 & 0.75 & 0.63 & 0.71 & 0.72 & 0.67 & 0.55 & 0.60 & 0.67 \\
\hline S2 & 0.71 & 0.79 & 0.72 & 0.69 & 0.68 & 0.70 & 0.84 & 0.78 & 0.69 & 0.63 & 0.59 & 0.68 \\
\hline S3 & 0.70 & 0.66 & 0.68 & 0.69 & 0.65 & 0.69 & 0.64 & 0.66 & 0.69 & 0.73 & 0.58 & 0.73 \\
\hline S4 & 0.72 & 0.70 & 0.70 & 0.74 & 0.71 & 0.70 & 0.68 & 0.70 & 0.65 & 0.75 & 0.62 & 0.71 \\
\hline S5 & 0.76 & 0.75 & 0.72 & 0.78 & 0.66 & 0.75 & 0.74 & 0.75 & 0.75 & 0.59 & 0.63 & 0.66 \\
\hline S6 & 0.74 & 0.79 & 0.75 & 0.74 & 0.72 & 0.79 & 0.81 & 0.78 & 0.77 & 0.67 & 0.65 & 0.72 \\
\hline
\end{tabular}

Table 6: Nash-Sutcliffe coefficient (NS) and log Nash-Sutcliffe coefficient of the simulated runoff by HBV, GR4J and HMETS models.

\section{Calibration and validation result of hydrological models}

Sensitivity analysis is conducted before the calibration process to identify the most important/sensitive parameters for each site, and model components. Insensitive parameters can be fixed to suitable values to decrease the dimensionality of the calibration problem. For six selected sites/catchments, the first one year of input data measurements were used for the "warming-up" of the models to estimate the initial state variables. The rest of the data were divided into two time periods, two-third of the data length for calibration (1971 to 2000) and one-third for validation (2001 to 2010) period for the three hydrological models. We considered the Nash/Sutcliffe and $\log$ Nash/Sutcliffe criterion as objective functions for calibration, which a statistical criterion is evaluating how much good the fit between observed and simulated values. The parameters of the hydrological models are optimized with SCE-UA method. We carefully, calibrated and validated these three hydrological models. Figure 4 compare the modeled hydrograph by three hydrological models and observed streamflow during the calibration period from July 1981 to July 1997 for illustrative purpose for two sites (site 1 and site 5, respectively). This reveal that the three models work well in the study basin in reproducing the historical flow and in simulation of flood peaks and low flows. All peak flows are captured with high accuracy except for the peak at lowland catchments, where the modeled peak occurred earlier and was lower than the observed.

The observed peak at site 2, which is located in the highland of the basin, the model captured the first peak well. The less pronounced over prediction of low flows by HBV compared to GR4J may indicate that the slow responding groundwater storage in HBV is less sensitive to different forecasted ensemble precipitation and temperature inputs. While HMETS behaves reasonably acceptable for high and medium flow. When we evaluate using the second objective function (LogNSE), the recession limbs of the hydrographs are generally better modeled than the rising parts; this can be attributed to the limited ability of the model to simulate longer wet-weather periods, which is simulated better using the first objective function (NSE). Therefore, in this study we considered LogNSE objective function for low flow indices simulation and NSE for high flow indices simulation.

Table 6 shows the result of statistical performance in calibration and validation period of the selected sites/catchments in upper Blue Nile River basin, Ethiopia using three hydrological models and two objective functions. The result of calibration and validation are ranging from 0.58 to 0.83 . It shows very good agreement between the observed and estimated flows. The three models confirm that they can reproduce historical streamflow series with an acceptable accuracy. However, the 


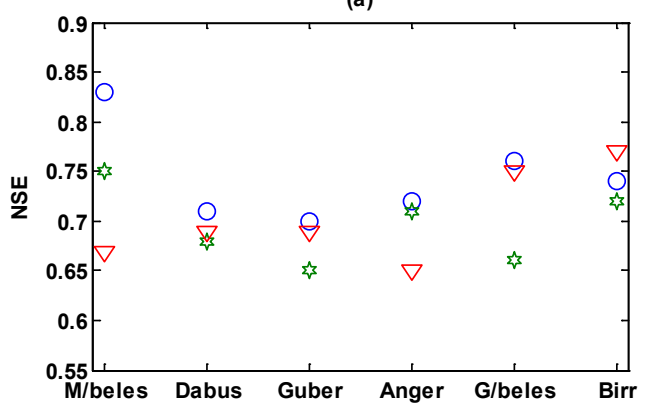

(c)

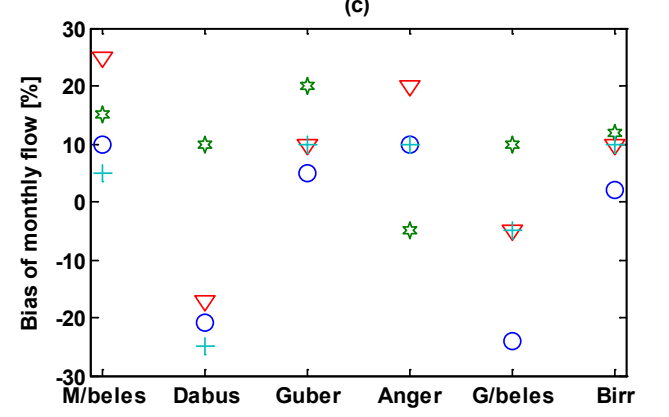

(b)

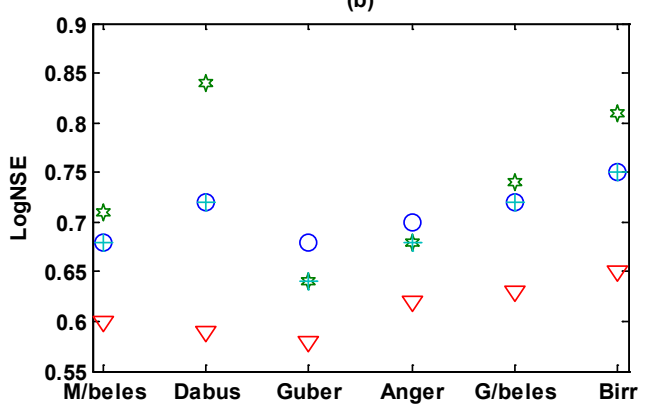

(d)

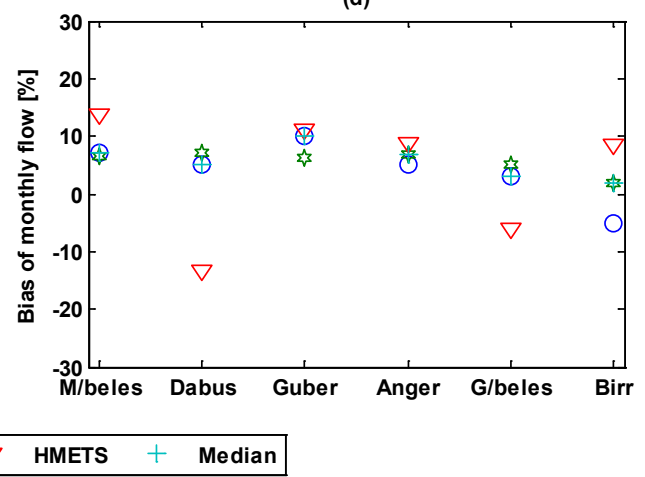

Figure 5: Distribution of selected model fit statistics across models by catchment for the flow time series from 1971 to 2000 ; (a) Nash-Sutcliffe Efficiency, (b) log NashSutcliffe Efficiency, (c) bias in mean max flow and (d) bias in mean min flow.

\begin{tabular}{|c|c|c|c|c|c|c|}
\hline & $\begin{array}{c}\text { Raw: RCP } \\
\mathbf{4 . 5}\end{array}$ & & & Corr: RCP 4.5 & & \\
\hline & Low & Max & Mean & Low & Max & Mean \\
\hline Site 1 & 59.5 & 37.4 & -16.9 & -9.5 & -11.3 & -4.7 \\
\hline Site 2 & 41.0 & 30.1 & -9.9 & 14.3 & 10.5 & -3.5 \\
\hline Site 3 & 29.8 & 19.2 & 11.8 & 10.4 & 6.7 & 4.1 \\
\hline Site 4 & 45.4 & -29.1 & 6.9 & 15.9 & -10.2 & 2.4 \\
\hline Site 5 & 49.4 & -35.3 & 9.9 & 17.3 & -12.4 & 3.5 \\
\hline Site 6 & 34.1 & -22.1 & 4.9 & 11.9 & -7.7 & 1.7 \\
\hline
\end{tabular}

Table 7: Influence of bias correction on hydrological extremes.

low flow was well produced using LogNSE objective function and the high flow is using NSE. So, in this study we use both objective functions for further analysis. When we compare among the hydrological models performance, HBV model has the highest NSE and GR4J has highest LogNSE values and the lowest NSE and LogNSE value by HMETS. The values in Table 6 demonstrate the basic capability of each model to reproduce daily observed streamflow in the selected sites in Blue Nile River basin, which shows that both GR4J and HBV models have high performance in reproducing historical high and low flow data for the study basins. This leads to notion of model complexity. In general, the performances of GR4J and HBV are similar in the calibration period, whereas HBV and HMETS performs better in the validation period. This is not surprising, since HBV has a more sophisticated model structure than GR4J and HMETS.

\section{Comparison of hydrological models}

In order to compare the performance of the three models, the daily discharge output of HBV, GR4J and HMTES is averaged to monthly max and min runoff, and the corresponding Nash-Sutcliff coefficient and log Nash-Sutcliff coefficient are computed according to equations (1) and (2). As is shown in Table 6 and Figure 5, the Nash-
Sutcliff coefficients of HBV, GR4J and HMTES at monthly scale for the period 1971-2000 are ranging 0.65 to 0.89 and the log Nash-Sutcliff coefficient are 0.58 to 0.83 , respectively. In Figure 5, it is found that the simulation by HBV does agree with the observation very well during 1971-2010 and the peak flow season in 1987, while the whole variation trend of simulation by GR4J model and HMETS model agree with the observation well. However, relatively HBV performs well over the other two. Both the HBV model and the GR4J model have a good physical basis, but the model performances of the two models are sometimes different. For example, the performance of GR4J model from late 1990 to early 1995 is not as good as the performance of HBV model, while the simulation for peak flow in 1997 of HBV model is better than that of GR4J model. The difference in model performance may be related to the model structure. The flow routing module of the three hydrological models are based on Muskingum method; however, there is still some difference in the structure of the three models.

Future hydrological changes were assessed based on output from HBV driven with the bias-corrected climate output from three climate scenarios (RCP 2.6, RCP 4.5 and RCP 8.5). To demonstrate the impact of bias correction on model results, Table 7 shows the discharge of six mainstream hydrological stations simulated by using HBV model driven by the raw and the bias-corrected output from three climate scenarios (RCP 2.6, RCP 4.5 and RCP 8.5), for the control period 1971-2000 and future period 2071-2100. Without the bias correction, the model overestimates both the peak streamflow and the low flow in control period. The relative errors of mean/maximum $/$ minimum annual runoff during this period simulated by using HBV model driven by the raw outputs of the climate models were $59.5,37.4$, and -16.9 $\%$. These errors were reduced to $-9.5,-11.3$, and $-4.7 \%$ after the biascorrected climate was used for site 1 . When the same bias correction method was used to drive future hydrologic simulations, a similar effect 

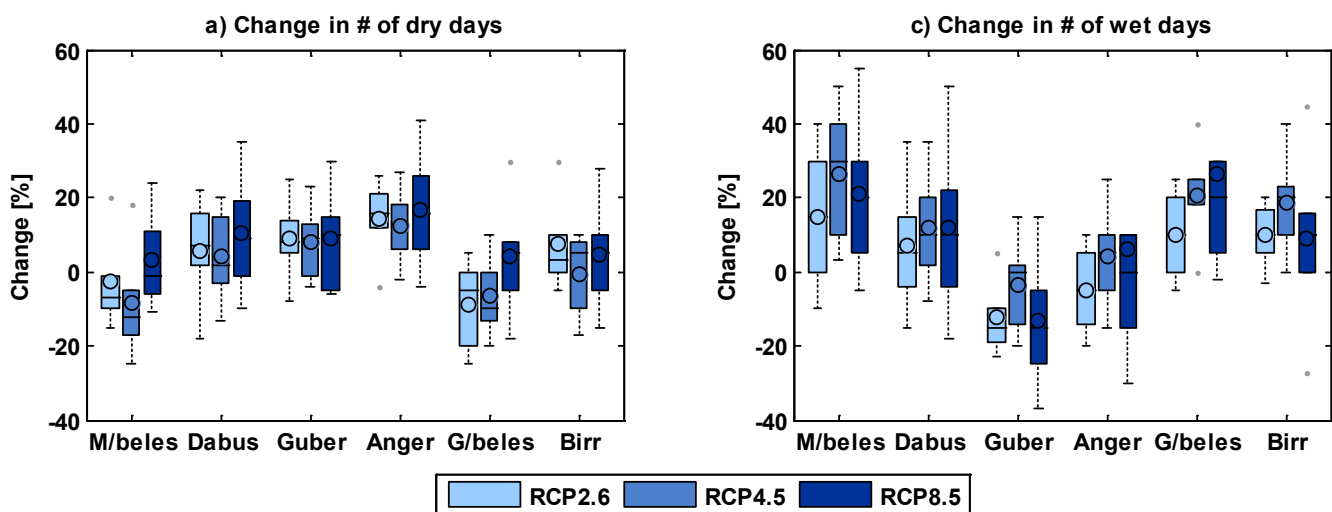

b) Change in max temp
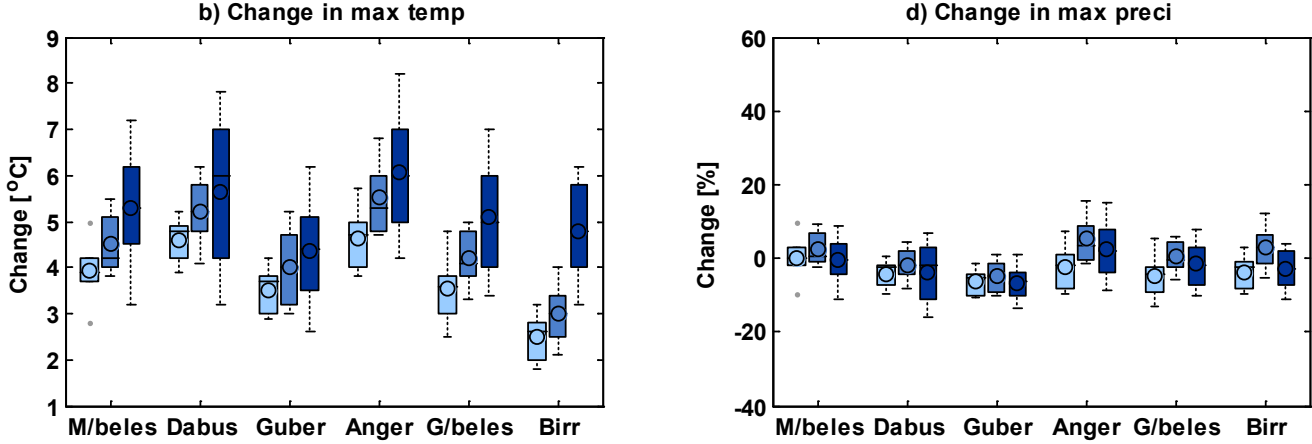

Figure 6: Estimated time series of MLDD (a), MLWD (b), ADMT(c) and ADMP (d) for six sites with different climate models. In each box, the central circle mark denotes a median from seven climate model simulations, the edges of the box are the $25^{\text {th }}$ and $75^{\text {th }}$ percentiles, the whiskers extend to the most extreme data points not considered as outliers, and outliers are plotted individually in the form of red crosses; the x-axis presents the list of six sites selected from the upper Blue Nile river basin.

is found, with reductions in the future base flow and peak flow (Table 7). Clearly visible that the importance of bias correction to simulate future hydrological extremes.

\section{Changes in hydrological, temperature and precipitation extremes}

In this session the changes in extremes of precipitation, temperature and streamflow are presented, respectively.

Changes in extreme precipitation and temperature indices: The projected changes of maximum wet spell (MLWD), maximum dry spell (MLDD), maximum precipitation (ADMP) and maximum temperature (ADMT) in the period of 2071-2100 relative to the reference period are shown in Figure 6. The MLWD index demonstrate that the future wet spell will be increase in most sites over the river basin except site 3 and site 4 . However, the degree/range of change is not the same in all sites. Large range change was observed in the lowland part of the basin (e.g. site 2). The MLWD change has higher variability than the MLDD and ADMP. There is a pronounced change except in the sites over central and north part of the river basin, where small decrease in the MLDD are expected with the maximum decrease reaching - $23 \%$. In these sites over the remaining areas of river basin, the MLDD change reaches up to $35 \%$. ADMP behaves with decreasing dominancy in the river basin. In the case of temperature, in all sites and climate scenarios in the river basin showed positive change for maximum temperature. This is may be because of the emission radian forcing direct relation with temperature and greenhouse gases. The main factor attributing to these changes is the impact of global warming on the temperature and precipitation patterns. Although the presence of short-length extreme wet spells and prolonged dry days, which will adversely affect the agricultural practices and water management in the country, is discernible from the analysis (Figure 6).

The three climate scenarios were show a consistency with decreasing in wet spell and increasing in wet spell and maximum temperature. However, the magnitude is different among the scenarios, which is larger variability and magnitude by RCP 8.5 and small by RCP 2.6 climate scenarios. Particular, RCP 8.5 reveals with higher magnitude and large change range. However, the RCP 2.6 and RCP 4.5 climate scenarios show more else reasonable result and relatively small difference in their future extremes prediction. The resean is related to the level of radiation emission forcing, the higher GHG emission has large effect on the wet/dry days in the region. The highest decrease in wet spell is occur in site one while the smallest is in site six. The remaining sites are show in between those maximum and minimum site values. The slight decrease in MLWD can be seen at the sites over upper-northern, and central part of the river basin by RCP 4.5 and RCP 2.6 climate scenarios (Figure 6).

As shown in Figure 7, in the period 2071-2100(2080s) there may be a decrease in mean monthly precipitation for all months except June, July, August, and September for three scenarios (RCP 2.6, RCP 4.5 and RCP 8.5). Decrease in annual mean precipitation for the 2080s and an increase for the kiremt season and decrease in belg season, which means the annual decrease in change is more dominant by belg than kiremt. The RCP 2.6 scenario displayed a mean monthly precipitation decrease up to $-20 \%$ in January and December and increase up to $18 \%$ in august and the RCP 4.5 also shows similar range of variability. While the RCP 8.5 behaves differently in all months with higher variability and large range of increase $(20 \%)$ and decrease $(-29.5 \%)$ value. generally increasing precipitation during the Kiremt (wet season 

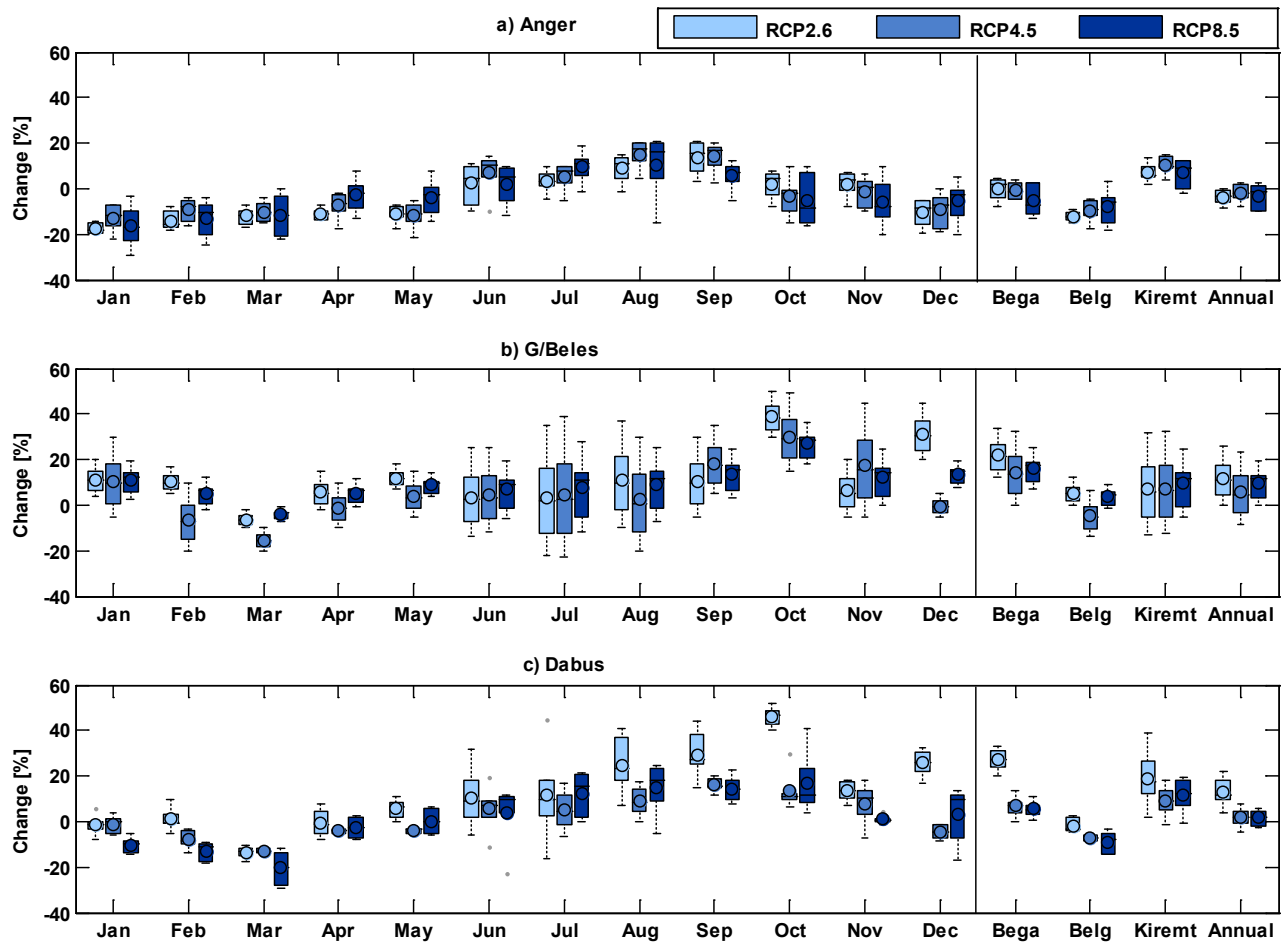

Figure 7: Percentage change in monthly, seasonal, and annual precipitation for the period 2071-2100 as compared to the reference period (1971-2000) at three sites (a) anger, b) G/Beles and C) Dabus). The three seasons are: Bega season (October-January), Belg season (February-May), and Kiremt season (June-September). In each box, the central circle mark denotes a median from seven climate model simulations, the edges of the box are the $25^{\text {th }}$ and $75^{\text {th }}$ percentiles, the whiskers extend to the most extreme data points not considered as outliers, and outliers are plotted individually in the form of red crosses; the x-axis presents the list of months, seasons and annual name.
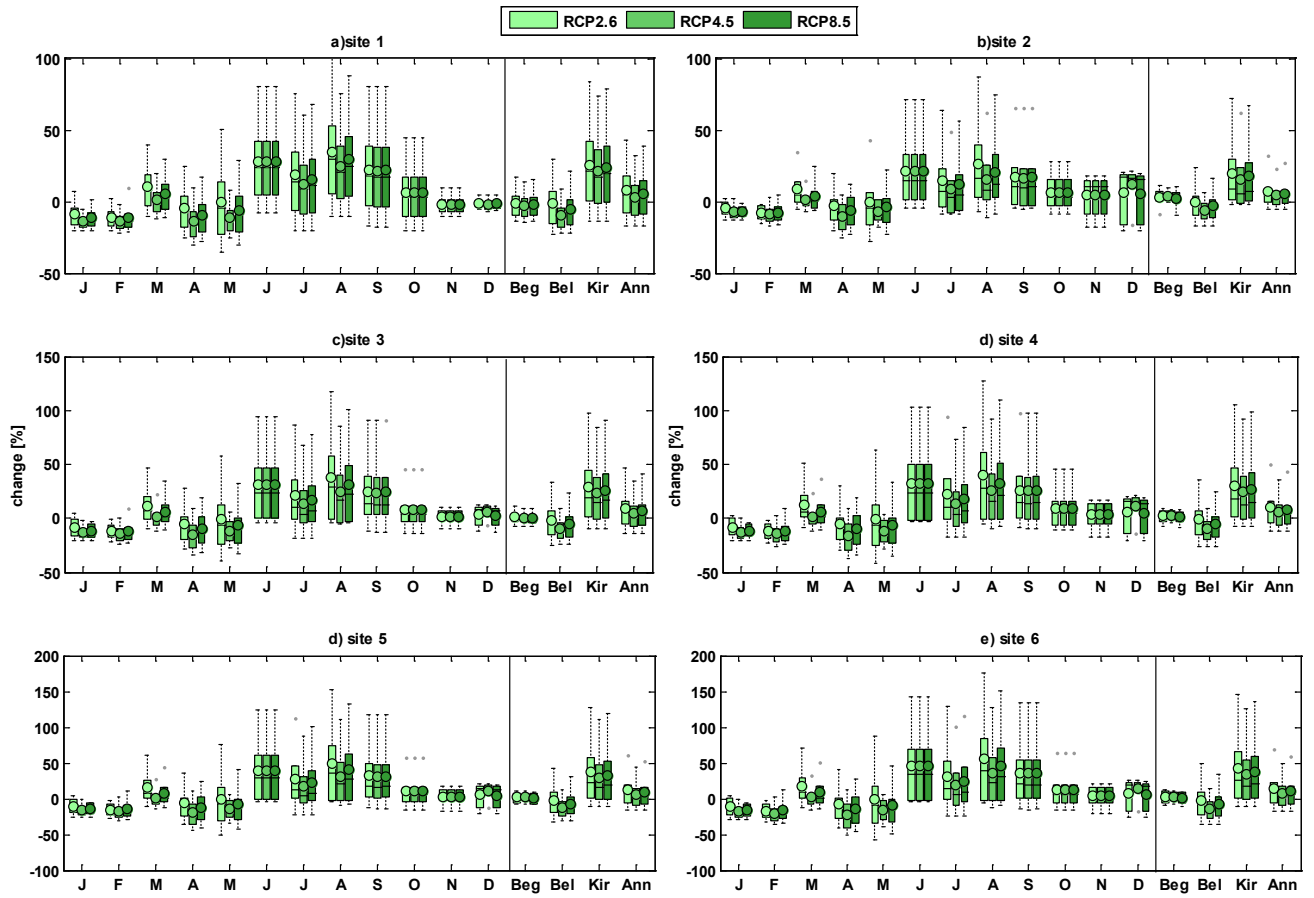

Figure 8: Projected monthly river discharge under climate change for 2071-2100 relative to 1971-2000. Climate change-rcp 4.5, rcp 2.6, rcp 8.5 ensemble mean, climate change-ensemble range. In each box, the central circle mark denotes a median from seven climate model simulations, the edges of the box are the $25^{\text {th }}$ and $75^{\text {th }}$ percentiles, the whiskers extend to the most extreme data points not considered as outliers, and outliers are plotted individually in the form of red crosses; the $\mathrm{x}$-axis presents the list of six sites selected from the upper Blue Nile river basin region. 


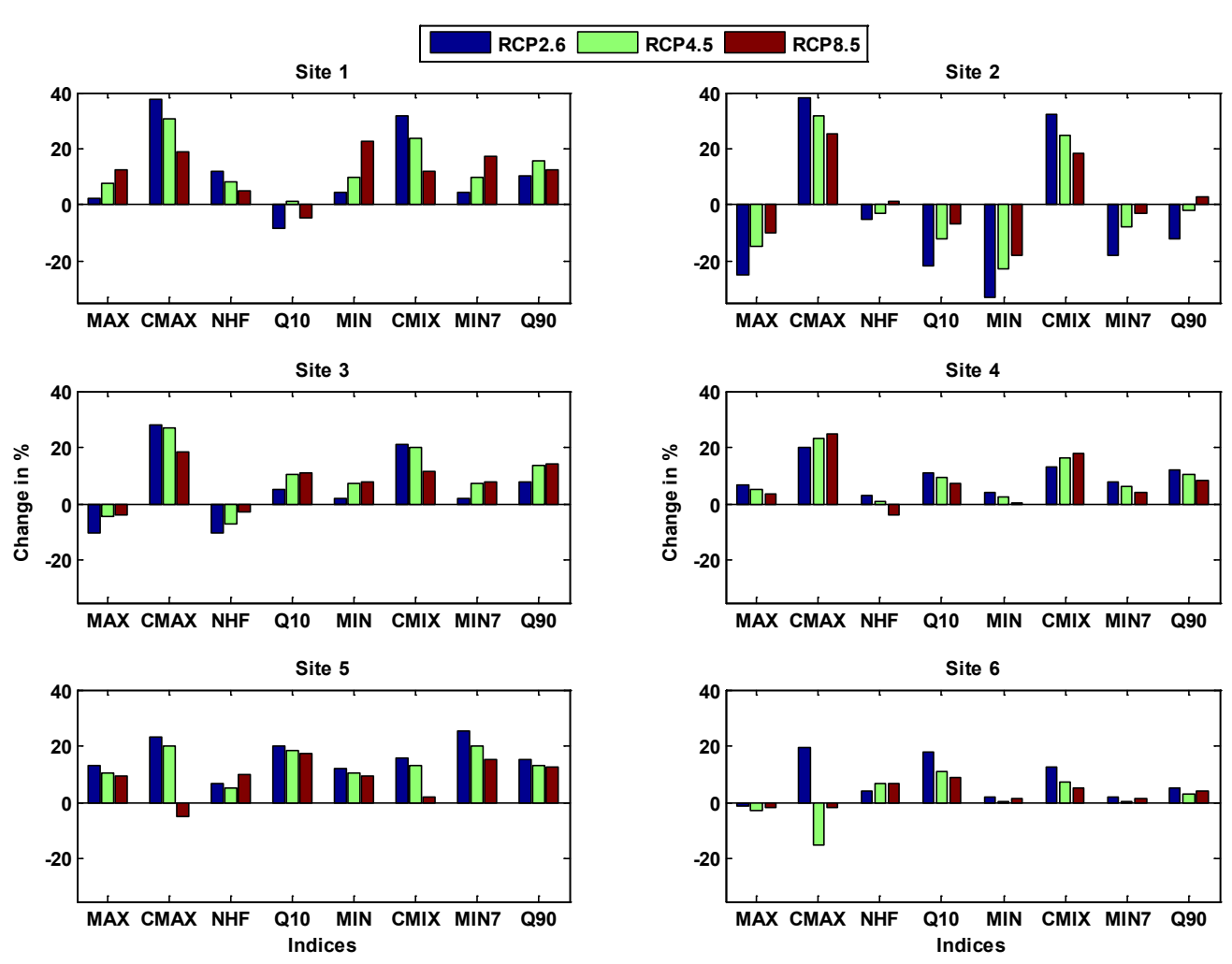

Figure 9: Expected changes in the selected characteristics of hydrological extremes for far future period (2071-2100). Y-axis is change in percent and x-axis is list of indices from both high and low flow.

(June-September)) for the long-term future. Results also indicate a corresponding decrease in precipitation for the Belg (less rainy season (February-May)) for 2080s. The Kiremit and Belg are the cropping seasons in Ethiopia. This gives an insight into the possible impact of climate change on agriculture in the study area.

Changes in hydrological extremes: The characteristics of hydrological extremes are calculated from the model outputs obtained from three future climate scenarios, and compared to the characteristics obtained from the reference data. The results of seasonal change and extremes per site change are presented in Figures 8 and 9 , respectively. The percentage change and variability of the climate models in the decadal average of monthly max flows for the projected 2071-2100 period versus the reference average monthly max values were calculated and are depicted in Figure 8. Generally, the scenario ensembles show lower monthly river flow at all considered stations, except for a large increasing in June, July, August and September. This means absolute discharge increases are more substantial in the wet season compared to those in the dry season. The ensemble's projection ranges become markedly larger in the wet season, implying higher uncertainty in the hydrological change signals. In terms of timing, the RCP 4.5 shows the largest increases in November, while the RCP 8.5 shows the largest increase in January, February and December. Although absolute increases are more substantial during the wet season months, relative increases are higher during the wet season. For instance, discharge in July and August could increase up to $65 \%$ at site $1,41 \%$ at site $3,150 \%$ at site 5 and $25 \%$ at site 4 . Despite the overall increasing trends, discharge in December, January and February are projected to reduce slightly at all six sites, ranging between $-8 \%$ at site 2 , followed by $-10 \%$ at site 6 and $-5 \%$ at site 4 . On the seasonal timescale, discharges increase at all stations during the wet seasons and the variability of GCMs/RCMs monthly discharge changes during the wet season are more variable compared to the dry season. This means that favorable water surplus conditions are more likely in the future during kiremt season. It does not require higher volumes of water to be stored to meet the dry season water demand if water storage projects such as the new Ethiopian Renaissance Dam (GERD) are constructed. Changes in the operation rules moreover become a necessity to deal with these changes in monthly flows ultimately.

The characteristics of changes in hydrological extremes are calculated from the model outputs obtained from three scenarios. In this study, the projected (2071-2100 period) flow indices were compared with the reference (1971-2000) period, which are presented in Figure 9. To assess the changes in flow extremes, the flow statistics that represent high and low flows were extracted from projected flow of the six sites. These flow statistics are termed MAX, CMAX, NHF, Q10, MIN, CMIX, MIN7, and Q90 and define the flows exceeding 90, and 10\% for the Q90 and Q10 flow from the flow duration curve, respectively. The first five indices are belonging to high flow characteristics of the basin and the last five are represents low flow characteristics of the basin, were computed to investigate how frequently these events occur.

Figure 9 presets the percentage changes of hydrological extreme statistics (MAX, CMAX, NHF, Q10, MIN, CMIX, MIN7, and Q90) of the six sites under three scenarios for 2080s period. CMAX and CMIX show a similar behaver in all sites, however the range of percentage change is different. The minimum flow shows lower variability than the high flows, which is maximum at sites 1 and 2 and minimum at site $6(17 \%)$. Whereas the CMIX varies $10 \%$ at site 6 to $28 \%$ at site 2. Whilst Q90 and Q10 does not show a similar range of percentage changes, which is Q10 changes - $20 \%$ at site 2 to $17 \%$ at site 5 while the 
range of changes in Q90 is much wider (-18\% at site 2 to $18 \%$ at site $5)$. This result can be explained by low-flow seasons, which is usually more sensitive to changes in potential evapotranspiration than highflow seasons. It is also partially because a relative percentage change value is magnitude-sensitive, e.g., the same increment or decrement gives a higher percentage change for low flows than for high flows. The increased low flows in this region suggest the increased low flow during the mild Belg season (February through May). The RCP 4.5 scenario projects almost a $-23 \%$ decreases in the magnitude of the MAX at site 2 and increase by $12 \%$ at site 5 . Under the RCP 8.5 scenarios, the increased temperature is in good accordance with the decrease in the magnitude of the MAX in site 2 and site 3. Also more kiremt flood events increase the number of high flows (NHF) by $6.5 \%$ at sites $1,5,6$.

In terms of extreme minimum flows, three of the scenarios project an increase in the MIN except at site 2 which is decrease by $10 \%$. The increase in the MIN values is around $22 \%$. Also the dry weather flow (MIN7) characteristics of minimum flows, which reflect a wider distribution of daily flows, increases by -18 to $22 \%$. The increase in minimum flows can be perhaps explained by the shift in the period of low flows from the beginning of August (baseline) toward the month of June, where the soil moisture storage is still affected by the wetter spring months. In terms of the magnitude of annual low flows, the evaluated scenarios project a $5-15 \%$ decrease in the CMIN characteristic. In a summary, low flows may become less extreme, less variable in terms of magnitude, and more variable in terms of temporal occurrence.

The presented results correspond well with the results published in other studies focused on upper Blue Nile River basin. For example, Kim et al., estimated a large increase in low flow and wider range $(-25 \%$ to $60 \%)$ slight increase in high flow and narrower range (-15\% to $20 \%)$ reduced severe drought events in the region. Aich et al., discussion also addressed an increase in high flows from $10 \%$ to $50 \%$ and an increase in low flows from $40 \%$ to $60 \%$ in the regfion.

\section{Conclusion}

This study assessed the expected climate change impact on hydrology extremes of selected six sites/catchments from the upper Blue Nile river basin and its implication on the water resource management and planning and disaster prevention and preparedness. Seven Regional Climate Model future projection runs viz. canESM2, CCM4, CNRM-CM5, CSIRO-Mk3.6.0, HadGEM2-ES, MIROC5, and MPIESM-LR were acquired and used for this purpose. The climate models run are based on the CMIP5 RCP 2.6, RCP 4.5, and RCP 8.5 scenarios. The run results for daily precipitation, and minimum and maximum temperatures were bias corrected against observed data using the distribution based quantile mapping (DQM) method for precipitation and temperature. The evaluation includes biases and measures for temporal and inter-variable consistency and is based on a split sample approach with strictly independent calibration and validation periods. Monthly biases are reduced by DQM to close to zero for all variables in most cases. Exceptions are found, when non-stationarities of the model's error characteristics occur. Those non-stationarities are not restricted to highly variable variables like precipitation and one particularly prominent case is found for temperature. Even in the worst cases of non-stationarity, DQM still clearly improves the biases of the raw RCM. We use independent calibration and validation periods, which are affected by climate variability and change. Thus, these results give some indication for the performance of DQM applied to future scenarios.

Projected changes of extremes derived from precipitation, temperature and streamflow for the future period over selected sites in the UBNRB. The changes are calculated for the future period (20712100) relative to the 1971-2000 reference period under the RCP 2.6, RCP 4.5 and RCP 8.5 emission scenarios, ensemble of seven climate model outputs were used in the calculations of the extreme precipitation and temperature indices (after bias-correction was applied): AMDP (the number of heavy rainfall days), MLDD (the annual maximum of consecutive dry days), MLWD (the annual maximum of consecutive wet days) and ADMT (annual daily maximum temperature). From the projection of extreme indices changes, we conclude that most areas of northern, western, and northeastern part of the river basin will likely become wetter in the wet season and drier in dry season. The MLWD index demonstrate that the future wet spell will be increase in most sites over the river basin except site 3 and site 4 . However, the degree/range of change is not the same in all sites. Large range change was observed in the lowland part of the basin (e.g. site 2). The MLWD change has higher variability than the MLDD and ADMP. There is a pronounced change except in the sites over central and north part of the river basin, where small decrease in the MLDD are expected with the maximum decrease reaching $-23 \%$. In these sites over the remaining areas of river basin, the MLDD change reaches up to $35 \%$. ADMP behaves with decreasing dominancy in the river basin. In the case of temperature, in all sites and climate scenarios in the river basin showed positive change for maximum temperature. This is may be because of the emission radian forcing direct relation with temperature and greenhouse gases. The main factor attributing to these changes is the impact of global warming on the temperature and precipitation patterns. Although the presence of short-length extreme wet spells and prolonged dry days, which will adversely affect the agricultural practices and water management in the country. This study concludes that the climate change is affecting the precipitation characteristics significantly and it brings variability in precipitation behavior.

In this study we compare three hydrological models in the reference period. The result confirms as conclusion $\mathrm{HBV}$ is more promising for future climate change impact study in the region. The climate change impact on the hydrological extremes in the 2080s has been carried out for the selected six river basins, Ethiopia. The lump conceptual hydrological model, HBV was used to estimate the hydrological extremes under climate change conditions. The extreme indices are calculated from projected flow, namely: MAX, CMAX, NHF, Q10, MIN, CMIN, MIN7, Q90, and change in the 2080s have been generated with respect to reference period. The assessment of climate change impact was based on $7 \mathrm{GCMs} / \mathrm{RCMs}$ simulation for RCP 2.6, RCP 4.5 RCP 8.5 emission scenarios. Overall, indices that related to low flows are projected to increase most prominently for lowland sites, due to the combined effects of projected decreases in summer precipitation, and projected increases in evapotranspiration that reduce residual soil moisture in late summer. Whereas the indices related to the high flows are projected slight increase in the central and upper part of the basin.

The projected changes in hydrologic extremes identified by this study have many implications for the built environment, the management of water resources, and natural resources. The projected shifts in flood magnitudes will likely impact existing infrastructure (e.g., roads, culverts, and bridges) designed to withstand less intense extremes, and may ultimately affect the design standards associated with the same infrastructure. Changes in floods and extreme low flows also affect water resources objectives such as water supply and reservoir operations for flood control and hydropower production. Increasing peak flows may affect water quality due to increased erosion and suspended sediment transport. Similarly, increasing peak flows may increase the transport of large woody debris in stream systems, 
altering aquatic habitat complexity, and damaging road infrastructure such as culverts and bridges. Maintaining minimum flows for fish is likely to become increasingly difficult over much of the region due to widespread declines in base flows in the Bega and Belg season.

This study made clear that climate change impact assessment is an extremely complex issue, hence, encouraging more research on this topic in order to increase awareness and to help improve further investigations and predictions is very important.

\section{Acknowledgments}

We acknowledge National Meteorological Agency and Ministry of Water Resource, Ethiopia, for providing meteorological and hydrological data.

\section{Author Contributions}

Hadush K Meresa performed the modeling strategy, analyzed the observed and future climate data, interpretation of the result, and wrote the paper. Mulusew T. Gatachew coordinated the data collection, supported the data analysis and writing, and proofread the paper.

\section{Conflicts of Interest}

The authors declare no conflict of interest.

\section{References}

1. Dupas R, Salmon-Monviola J, Beven K, Durand P, Haygarth PM, et al. (2016) Uncertainty assessment of a dominant-process catchment, model of dissolved phosphorus transfer. Hydrol Earth Syst Sci 545.

2. Towler E, Rajagopalan B, Gilleland E, Summers RS, Yates D (2010) Modeling hydrologic and water quality extremes in a changing climate: A statistical approach based on extreme value theory. Water Resour Res 46: 0043-1397.

3. Taye MT, Willems P, Block P (2015) Implications of climate change on hydrological extremes in the Blue Nile basin: a review. J Hydrol: Regional Stud 4: $280-293$.

4. Chaney NW, Sheffield J, Villarini G, Wood EF (2014) Development of a high resolution gridded daily meteorological data set over Sub-Saharan Africa: Spatial Analysis of Trends in Climate Extremes. J Climate 27: 5815-5835.

5. World Meteorological Organization (2015) Valuing weather and climate: Economic Assessment of Meteorological and Hydrological Services, WMO-No. 1153.

6. Zhang L, Nan Z, Xu Y, Li S (2016) Hydrological impacts of land use change and climate variability in the headwater region of the Heihe River Basin, Northwest China. PLoS ONE 11: e0158394.

7. Intergovernmental Panel in Climate Change (IPCC) (2013) Summary for policymakers. In: Climate Change 2013: The physical science basis Contribution of Working Group I to the Fifth Assessment Report of the Intergovernmental Panel on Climate. Cambridge University Press, Cambridge, UK and New York, NY, USA.

8. Mawada A, William A, Rafid A (2012) Climate change impacts on the extreme rainfall for selected sites in North Western England. Open J Modern Hydrol 2: 49-58.

9. Chen J, Brissette FP, Leconte R (2011) Uncertainty of downscaling method in quantifying the impact of climate change on hydrology. J Hydrol 401: 190-202.

10. Vrac M, Naveau P (2007) Stochastic downscaling of precipitation: From dry events to heavy rainfalls. Water Resour Res 43: W07402.

11. Meresa KH, Marzena O, Romanowicz R (2016) Hydro-meteorological drought projection in $21^{\text {st }}$ century in selected catchments in Poland. Water 8: 206

12. Gelfan AN, Semenov VA, Motovilov Yu G (2015) Climate noise effect on uncertainty of hydrological extremes: numerical experiments with hydrological and climate models. P IAHS 369: 49-53.

13. Hattermann FF, Huang S, Burghoff O, Willems W, Österle, H, et al. (2014) Modelling flood damages under climate change conditions a case study for Germany. Nat Hazards Earth Syst Sci 14: 3151-3169.

14. Paul Gorman AO (2015) Precipitation Extremes under climate change. Curr Clim Change Rep 1: 49-59.

15. Hattermann FF, Kundzewicz ZW, Huang S, Vetter T, Kron W, et al. (2012) Flood risk in holistic perspective observed changes in Germany, In: Changes in flood risk in Europe, Wallingford, Oxfordshire, UK, 2012, vol. Special Publication No. 10, IAHS Press, 212-237.

16. Te Linde AH, Bubeck P, Dekkers JEC, De Moel H, Aerts JCJH (2011) Future flood risk estimates along the river Rhine. Nat. Hazards Earth Syst Sci 11 459-473.

17. Taye MT, Ntegeka V, Ogiramoi NP, Willems $P$ (2011) Assessment of climate change impact on hydrological extremes in two source regions of the Nile River Basin. Hydrol Earth Syst Sci 15: 209-222.

18. Haong L, Hannu L, Matti K, Jorma K, Michelle TH, et al. (2016) Mekong river flow and hydrological extremes under climate change. Hydrol. Earth Syst Sci 20: 3027-3041.

19. IPCC Climate Change (2001) The science of climate change. Third Assessment Report of the Intergovernmental Panel on Climate Change, Cambridge University Press, Cambridge, UK.

20. Dessu SB, Melesse AM (2013) Impact and uncertainties of climate change on the hydrology of the Mara River basin, Kenya/Tanzania Hydrol Processes 27 2973-2986.

21. Osuch M, Romanowicz RJ, Lawrence D, Wong WK (2015) Assessment of the influence of bias correction on meteorological drought projections for Poland Hydrol Earth Syst Sci Discuss 12: 10331-10377.

22. Solomon S (2007) Climate change 2007-the physical science basis: Working group I Contribution to the Fourth Assessment Report of the IPCC (Vol. 4),2007, Cambridge University Press, 996 pp.

23. Ministry of Water Resources (1999) Abbay River Basin Integrated Development Master Plan Project: Main Report Phase 3. BECOM-French Engineering Consultants in collaboration with BRGM and ISL, Addis Ababa, Ethiopia.

24. Seleshi Y, Zanke U (2004) Recent changes in rainfall and rainy days in Ethiopia Int J climatol 24: 973-983.

25. Hamon WR (2016) Computation of direct runoff amounts from storm rainfall. In Assoc Sci Hydrol Pub 63: 52-62.

26. Lu J, McNulty SG, Amatya DM (2005) A comparison of six potentia evapotranspiration methods for regional use in the southeastern USA. J Am Water Res Assoc 41: 621-633.

27. Giorgi F, Jones C, Asrar GR (2015) Addressing climate information needs at the regional level: the CORDEX framework. Bulletin of the World Meteorological Organization. 58: 175-183.

28. Taylor KE, Stouffer RJ, Meehl GA (2012) An overview of CMIP5 and the experiment design. B Amer Meteor Sco 93: 485-498.

29. Thomson AM, Calvin KV, Smith SJ, Kyle GP, Volke A, et al. (2011) RCP4.5 a pathway for stabilization of radiative forcing by 2100 . Climatic Change 4 : 10584-110151.

30. Van Vuuren DP, Riahi K (2011) The relationship between short-term emissions and long-term concentration targets a letter. Climatic Change 104: 793-801.

31. Riahi K, Krey V, Rao S, Chirkov V, Fischer G, et al. (2011) RCP-8.5: exploring the consequence of high emission trajectories. Climatic Change 10584-110149.

32. Christensen JH, Boberg F, Christensen OB, Lucas-Picher $P$ (2008) On the need for bias correction of regional climate change projections of temperature and precipitation. Geophys Res Lett L20709.

33. Piani C, Haerter JO, Coppola E (2010) Statistical bias correction for daily precipitation in regional climate models over Europe. Theor Appl Climatol 99: 187-192.

34. Rojas R, Feyen L, Dosio A, Bavera D (2011) Improving Pan-European hydrological simulation of extreme events through statistical bias correction of RCM-driven climate simulations. Hydrol Earth Syst Sci 15: 2599-2620.

35. Bergström S (1995) The HBV model. In: Computer models of watershed hydrology. Singh VP. (ed.) Water Resources Publications, Highlands Ranch, Colorado USA 443-476.

36. Blöschl G, Ardoin-Bardin S, Bonell M (2007) At what scales do climate variability and land cover change impact on flooding and low flows? Hydrological Processes 21: 1241-1247.

37. Bergström S (1976) Development and application of a conceptual runoff mode for Scandinavian catchments. SMHI RHO 7, Norrköping, 134 pp.

38. Boukhaly TV, Soussou S, Séni T, Sidy F, Amadou TD, et al. (2014) Calibrating the rainfall-runoff model GR4J and GR2M on the Koulountou River Basin, Tributary of the Gambia River. Am J Environ Protection 3: 36-44. 
Citation: Meresa HK, Gatachew MT (2016) Modeling of Hydrological Extremes Under Climate Change Scenarios in The Upper Blue Nile River Basin, Ethiopia. J Civil Environ Eng 6: 252. doi: 10.4172/2165-784X.1000252

39. Demirel MC, Booij MJ, Hoekstra AY (2013) Effect of different uncertainty sources on the skill of 10 day ensemble low flow forecasts for two hydrological models. Water Resour Res 49: 4035-4053.

40. Perrin Andre'assian M (2003) Improvement of a parsimonious model for streamflow simulation. J Hydrol 58: 145-251.

41. Tian S, Youssef MA, Skaggs RW, Amatya DM, Chescheir GM (2012) Modeling water, carbon, and nitrogen dynamics for two drained pine plantations under intensive management practices. Forest Ecol and Mgmt 264: 20-36.

42. Thyer M, Renard B, Kavetski D, Kuczera G, Franks SW, et al. (2009) Critical evaluation of parameter consistency and predictive uncertainty in hydrological modeling: A case study using Bayesian total error analysis, Water Resour Res 45: W00B14

43. Pushpalatha R, Perrin C, Moine NL, Mathevet T, Andreassian VA (2011) Downward structural sensitivity analysis of hydrological models to improve lowflow simulation. J Hydrol 411: 66-76.

44. Brissette FP, Chen J, Leconte R (2010) Uncertainty of downscaling method in quantifying the impact of climate change on hydrology. J Hydrol 401: 190-202.

45. Arsenault R, Gatien P, Renaud B, Brissette F, Martel JL (2015) A comparative analysis of 9 multi-model averaging approaches in hydrological continuous streamflow prediction. J Hydrol 529: 754-767.

46. Duan QY, Sorooshian S, Gupta VK (1992) Effective and efficient global optimization for conceptual rainfall-runoff models. Water Resour Res 28: 1015-1031.

47. Duan QY (1991) A global optimization strategy for efficient and effective calibration of hydrologic models. Dissertation for the Doctoral Degree. Arizona: University of Arizona.

48. Duan Q (2003) Calibration of watershed models. Q. Duan, H. Gupta, A. N Sorooshian (Eds.) AGU, Washington, D.C Water Sci Appl 6: 89-104.

49. Nash JE, Sutcliffe JV (1970) River flow forecasting through conceptual models, Part I - A discussion of principles, J Hydrol 10: 282-290.

50. Kim U, Kaluarachchi JJ, Smakhtin VU (2008) Climate change impacts on hydrology and water resources of the Upper Blue Nile River Basin, Ethiopia International Water Management Institute, Colombo, Sri Lanka 27, IWM Research Report 126.

51. Aich V, Liersch S, Vetter T, Huang S, Tecklenburg J, et al. (2014) Comparing impacts of climate change on streamflow in four large African river basins. Hydrol Earth Syst Sci 18: 1305-1321. 